\title{
Letters
}

Website: bmj.com

Email: letters@bmj.com

\section{Randomised controlled trials for homoeopathy}

\section{Providers have much to gain from} homoeopathy being accepted

EDITOR-Debates generated by the lack of evidence of benefit of screening for breast and prostate cancer are similar to the argument for lack of effectiveness of homoeopathy. How does one show a lack of benefit in the face of wishful thinking by both customers and providers, particularly when the providers have a financial interest in a positive outcome? And, as an anaesthetist and non-user of any of these services, why should I care?

The answer is given by Feder and Katz, who point out that patients can be referred to homoeopathic specialists in the NHS or general practitioners who prescribe homoeopathically. ${ }^{1}$ Consumers of these resources should have a duty to show a benefit from any consultations or treatments provided, and the fundholders should have a duty to withhold funds in the absence of such evidence. If the customers then wish to purchase treatment that is not beneficial they will of course be free to do so and the homoeopaths, iridologists, colonic irrigationists, and the rest can flourish.

As the editorial points out, meta-analysis of results of trials of homoeopathic treatments suggest benefit greater than placebo in some cases, but this can easily be discounted by publication bias. Statistically, some trials of homoeopathic treatments will show some benefit even when the real effect of the treatment is zero, and these are the trials that are most likely to be published.

Homoeopaths argue that their treatments are not amenable to statistical analysis in the same way as conventional medicine is, in part because most trials of homoeopathic medicines do not individualise treatment. I can give an example from my own practice: anaesthesia for coronary artery surgery. In this, treatment is tailored to individuals, whose coronary anatomy is unique, yet statistical analysis shows an aggregate beneficial effect from treatment. This is how medicine works; patients are individuals yet patterns can be recognised, and this allows us to base our diagnostic and therapeutic interventions on these patterns.

Why should homoeopathy be allowed to hide behind a smokescreen that is denied to conventional medicine, and why should the NHS fund such treatment in the absence of any evidence of useful effect?
The answer is that the providers have a lot to gain, in terms of financial reward and intellectual acceptance; quacks will always be with us.

Michael Foley consultant anaesthetist James Cook University Hospital, Middlesbrough TS4 3BW

mikefoley@doctors.org.uk 1 Feder G, Katz T. Randomised controlled trials for homoe-
opathy. BMJ 2002;324:498-9. (2 March.)

\section{Studies comparing homoeopathy and} placebo are unhelpful

EDITOR-Why do we need another study comparing homoeopathy with placebo? The word placebo is a language construct for an apparently inert product, just as the word homoeopathy is a language construct for treatment with an apparently active product. We know that both may have positive effects on an illness, and occasionally one of the interventions will be more effective than the other. But when both are studied against an effective active treatment no difference is found between them. ${ }^{2}$

Clinicians must decide whether to prescribe effective active treatment that is significantly better than placebo or homoeopathy. For mild illness, where the active treatment leads to small benefits or high risks, a placebo or homoeopathy can be chosen. For severe illness, where the active treatment leads to large benefits, the active treatment can be chosen. There will be a grey zone.

Our debate should really be about the extent of this grey zone. It is certainly different in Australia from that in the United Kingdom, where five times more general practitioners are involved with homoeopathy. ${ }^{45}$ Why is this? Differences in health funding? Availability and costs of active treatments? Cultural differences? These are some of the questions worth studying, rather than spending our resources on further trials of homoeopathy versus placebo.

John Weiner visiting allergist

St Vincent's Hospital, Fitzroy, Victoria 3065, Australia

jmweiner@allergynet.com.au

1 Lewith GT, Watkins AD, Hyland ME, Shaw S, Broomfiel JA, Dolan G, et al. Use of ultramolecular potencies of allergen to treat asthmatic people allergic to house dust mite: double-blind randomised controlled clinical trial. $B M J$ 2002;324:520-3. (2 March.)

2 Fisher P Scott DL A randomised controlled trial of homeopathy in rheumatoid arthritis. Rheumatology 2001;40 $1052-5$.

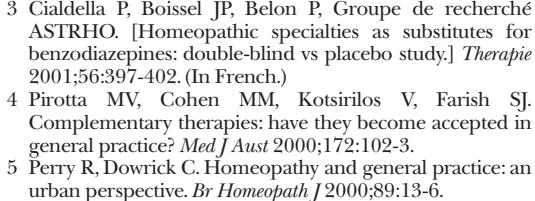

3 Cialdella P, Boissel JP, Belon P, Groupe de recherché ASTRHO. [Homeopathic specialties as substitutes for benzodiazepines: double-blind vs placebo study.] Therapie 2001;56:397-402. (In French)

4 Pirotta MV, Cohen MM, Kotsirilos V, Farish SJ Complementary therapies: have they become accepted in general practice? Med J Aust 2000;172:102-3.

5 Perry R, Dowrick C. Homeopathy and general practice: an urban perspective. Br Homeopath J 2000;89:13-6.

\section{Language is being distorted}

EDITOR-The conclusion in the abstract to Lewith et al's paper states: "Homoeopathic immunotherapy is not effective in the treatment of patients with asthma."1 The last sentence of the paper itself states: "In conclusion, in this double blind, randomised controlled trial of homoeopathic immunotherapy we have failed to confirm that this treatment is therapeutically efficacious in allergic asthma." These two conclusions are not the same.

The conclusion of the paper is a reasonable one to make. "In this trial we have failed to confirm" captures the point exactly. To extrapolate that to the conclusion quoted in the abstract suggests that no homoeopathic immunotherapy is ever effective in patients with asthma; this is not logical. What if a different potency or different frequency of dosing were to show a difference? This trial only used three doses of 30c over 24 hours. Many other different regimens are used in practice. This trial doesn't show that those other regimens don't work.

Sadly, this loose use of language then generates front page headlines like the one on the cover of the 2 March issue, which says: "Homoeopathy for dust mite allergies? No, it's a waste of time." This further extrapolates from the conclusion of the abstract to claim that any use of homoeopathy in treating dust mite allergies is a waste of time. This is an even less defensible position.

So, from article to conclusion, to conclusion of the abstract, to front page headline we lose the truth and develop generalisations that are not only wrong but unscientific.

Robert W Leckridge associate specialist Glasgow Homoeopathic Hospital, Glasgow G12 0XQ

bob.leckridge@virgin.net

1 Lewith GT, Watkins AD, Broomfield JA, Dolan G, Holgate ST. Use of ultramolecular potencies of allergen to treat asthmatic people allergic to house dust mite: double blind randomised controlled clinical trial. BMJ 2002;324:520-3. (2 March.)

\section{Study is in effect trying to compare} apples with oranges

EDitoR-Homoeopathy is a system of healing that has been around for over 200 years. It does not operate in the way that allopathic medicine does. 
Allopaths treat symptoms. They say that if patient $\mathrm{A}$ has a certain set of symptoms then a specific drug will be used for treatment. All patients are treated on the basis of their symptom picture. Sometimes a history is taken to ensure that patients are not allergic to a certain drug; if they are, then another one will be substituted. But, generally, allopathy will treat symptoms rather than the whole person.

Homoeopathy treats the person. If a person has asthma a homoeopath will generally spend at least one hour on a first visit, getting an idea of the person's history and lifestyle. What is his/her diet like? What other problems has $\mathrm{s} /$ he been treated for in the past? Are there any emotional issues? Then, and only then, will a remedy be prescribed, based not on the symptoms that the patient has but on what the homoeopath thinks is causing those symptoms. Only then can someone truly be cured.

Lewith et al's study does not compare homoeopathic and allopathic treatments of asthma. ${ }^{1}$ It sets out with the intention of proving that homoeopathy does not work. To accomplish this it is using nonhomoeopathic treatments and methods.

I have never heard of a homoeopath using potentised allergens to treat an allergy, although possibly in some cases this might be an effective treatment. Certainly, if you took 242 people with asthma and treated them homoeopathically you might well find that they would require 242 different remedies.

How is it possible that something as ill constructed and ill conceived as this study could be published in the BMT? Where were the peer reviewers when the paper was submitted? Does the $B M J$ have any homoeopaths as reviewers, or was the paper looked at by people who are as ignorant of homoeopathy as the authors obviously are?

When I read something of this nature in the $B M J$ I truly wonder what other studies make it through the peer review process for absolutely no good reason.

Meryl Dorey national presiden

Australian Vaccination Network Inc, PO Box 177, Bangalow NSW 2479, Australia

meryl@avn.org.au

1 Lewith GT, Watkins AD, Broomfield JA, Dolan G, Holgate ST. Use of ultramolecular potencies of allergen to treat asthmatic people allergic to house dust mite: double blind randomised controlled clinical trial. BMJ 2002:324:520-3. (2 March.)

\section{When is useful improvement a waste of time? Double positive paradox of negative trials}

EDITOR-Lewith et al report a pilot study of the use of homoeopathic immunotherapy, ${ }^{1}$ complementing but differing from Reilly et al's earlier study. ${ }^{2}$

The table accompanying this letter is published on bmj.com, as is a rapid response from me. ${ }^{3}$ The table lists some of the fundamental differences between the two trials that may have determined their different results, and my rapid response may also clarify matters. Lewith et al's data show day to day effectiveness but leave a question mark over the efficacy issue of "more than placebo." Taylor et al's series suggested efficacy more than placebo in homoeopathy but did not tackle effectiveness.

In Reilly et al's trial only the active group improved; in Lewith et al's both the placebo and active groups improved. The cover of the 2 March issue of the $B M J$ has an italic headline saying that homoeopathic immunotherapy is a waste of time. But the graphs of subjective and objective variables in both groups in Lewith et al's paper show the effectiveness of homoeopathy in an everyday context for a common and serious disease. We have created a curious intellectual and clinical absurdity here-useful improvement that is a waste of time.

Perhaps it is now time to ask of a negative study whether it is a "double positive" study (both groups improving) or a "double negative" study (neither group improving). This question is important because each scenario calls for different conclusions, debate, and treatment in systematic reviews. If we reject double positive trials without due care we risk the paradox of throwing out treatments with efficacy exactly because they also show high effectiveness-when the real problem is that our studies lack the power to see the baby of efficacy in its bath water of "context/non-specific/placebo" effectiveness. In a double negative study there is neither baby nor bath water.

Lewith et al's study may well have obtained false negative results, finding it hard to show additional activity over excellent context induced improvements-rather like the failure of sertraline and St John's wort (Hypericum perforatum) to better placebo facilitated improvement in depression ${ }^{5}$; that study was another double positive study (or triple positive in that case) that has been reported in the media as yielding a negative result. The $B M$ Ps classification of homoeopathy as a negative treatment is premature.

David Reilly lead consultant physician Glasgow Homoeopathic Hospital, Glasgow G12 OXQ davidreilly1@compuserve.com

\section{The table is published on bmj.com}

1 Lewith GT, Watkins AD, Broomfield JA, Dolan G, Holgate ST. Use of ultramolecular potencies of allergen to treat asthmatic people allergic to house dust mite: double blind asthmatic people allergic to house dust mite: double blind 2 March.

2 Reilly DT, Taylor MA, Campbell J, Beattie N, McSharry C Aitchison T, et al. Is evidence for homoeopathy reproducible? Lancet 1994;344:1601-6.

3 Reilly D. A pilot design of diluted power. It might prove effectiveness, but it does not disprove efficacy. bmj.com cgi/eletters/324/7336/520\#20216 (accessed 26 Jun 2002)

4 Taylor MA, Reilly D, Llewellyn-Jones RH, McSharry C, Aitchison TC. Randomised controlled trial of homoeopathy versus placebo in perennial allergic rhinitis with overview of four trial series. BMI 2000:321:471-6.

5 Hypericum Depression Trial Study Group. Effects of (St Joh, Group. Elfects of Hypericum perforatum (St John's wort) in majo 2009:287:1807-14.

\section{Authors' reply}

EDITOR-Homoeopathy arouses strong emotions among believers and nonbelievers, as the extent of responses to our article suggests; our letter encompasses the points made electronically and above.
Homeopathy is a "waste of time," states the front cover of the BMJ. This type of response to our scientific paper is inaccurate and unhelpful. We tested the model of homoeopathic immunotherapy as suggested and defined by Reilly et al and observed no clinical effect. ${ }^{1}$ However, as pointed out in our paper, we recognise that this model is not generalisable into current homoeopathic practice. It was used to investigate the different effects of ultramolecular potencies compared with placebo rather than pragmatic homoeopathy.

Feder and Katz suggest that the mechanisms underpinning homoeopathy are best understood through laboratory experimentation. We believe that clinical investigations in humans offer insights that are impossible to achieve in a laboratory. We have suggested some hypotheses that might explain our observed oscillatory effects of homoeopathy, but these require further work $^{2}$; they may be a type I error. We hope that Feder and Katz's suggestion about pragmatic studies does not represent a retreat from rigour.

One reason for conducting our study was that we were concerned by the small size and potential for statistical error and the atypical lack of improvement over time for placebo in the asthma study of Reilly et al. Our study owes much to the design of this earlier work, but it was not a mere duplication. We rigorously rediagnosed asthma in each patient, and before the study we communicated with Reilly to check that we were following the same protocol in relation to inclusion criteria, dosage regimen, and primary outcome (visual analogue scale). ${ }^{1-3}$ Reilly suggests that he used repeated doses of homoeopathic immunotherapy but does not report this in his asthma study. ${ }^{1}$ We were also not aware that each patient was subjected to an individual case conference with, possibly, unreproducible inclusion criteria.

It has been suggested that a hospital based study would select a different population of patients from those in general practice. There is no evidence that this is the case; many high quality asthma effectiveness studies have been conducted in primary care. We selected a group of asthmatic patients in two neighbouring counties who had variable asthma so we could measure change. We cannot understand Reilly's hypothetical differentiation between an effectiveness and efficacy study in this context.

Like us, Taylor et al avoided the pollen season and used potencies of house dust mite while not avoiding the house dust mite season. ${ }^{4}$ The use of Reilly's visual analogue scale on alternate weeks avoided patient data recording fatigue and produced greater compliance over a 20 week study. Our process of randomisation entailed minimisation, thus balancing the treatment groups. Both nurses and patients were unable to guess trial allocation, therefore we are clear that our blinding allocation was completely secure. Had we used a different time point for analysis we might have obtained different (false positive) results. 
We analysed response to homoeopathic immunotherapy over 4 months and as a consequence our conclusions are less open to misinterpretation. The only major methodological difference between our study and that of Reilly et al is the lack of a placebo run-in period; an unlikely cause of a significant difference in outcome. ${ }^{1}$

Homoeopathic immunotherapy may be effective in rhinitis, ${ }^{3}{ }^{4}$ but independent investigations have failed to confirm this. ${ }^{5}$ Reilly may have overinterpreted one small such study on asthma. We accept that no two clinical trials are exactly the same, but we believe our study is comparable. It comes to different conclusions about the differences between homoeopathy and placebo and about treatment effect, reporting that homoeopathy and placebo are significantly different. The robustness of these observations requires careful further work rather than more debate.

George T Lewith senior research fellow Complementary Medicine Research Unit, Mail Point OPH, Royal South Hants Hospital, Southampton SO14 0YG

Michael Hyland professor of health psychology Department of Psychology, University of Plymouth, Plymouth PL4 8AA

Stephen Holgate clinical professor of

immunopharmacology

Respiratory, Cell and Molecular Biology Division, Mailpoint 810, Southampton General Hospital,

Southampton SO16 6YD

Reilly D, Taylor MA, Beattie NGM, Campbell JH, McSharry $\mathrm{C}$, Aitchison TC, et al. Is evidence for homoeopathy reproducible? Lancet 1994:344:1601-6.

2 Hyland ME, Lewith GT. Oscillatory effects in a homeopathic clinical trial: an explanation using complexity pathic clinical trial: an explanation using complexity
theory, and implications for clinical practice. Homeopathy

3 Reilly DT, Taylor MA, McSharry C, Aitshison T. Is homoeopathy a placebo response? Controlled trial of homoeopathic potency, with pollen in hayfever as model. Lancet 1986;ii:881-6.

4 Taylor MA, Reilly D, Llewellyn-Jones RH, McSharry C, Aitchison TC, Lancaster T, et al. Randomised controlled trial of homoeopathy versus placebo in perennial allergic rhinitis with overview of four trial series. $B M$ J 2000;321:471-6.

5 Aabel S. No beneficial effect of isopathic prophylactic treatment for birch pollen allergy during a low-pollen season: a double-blind, placebo-controlled clinical trial of homeopathic Betula 30c. Br Homeopath J 2000;89:169-73.

\section{Evidence based leaflets in maternity care}

Compliance, coercion, and power have huge effect in maternity services

EDITOR-The midwives from Sheffield show the insight that a qualitative study can provide when coupled with a more controlled empirical investigation. ${ }^{12}$ Both the studies and the accompanying editor's choice suggest that inequalities in power and status in the maternity services have a greater influence on what happens to women giving birth than either their hopes and dreams or the choices they feel informed to make. ${ }^{3}$

These studies are a powerful reminder that the physiological birth process without some degree of technological interference and tampering is rare. Midwives are portrayed in this hierarchical system as having little effect on the outcome of care. The authors suggest that when women can form a trusting relationship with a midwife they are more likely to ask questions and feel that they can make choices about their care, rather than simply being compliant.

As members of a national consumer movement in Australia, we consider it to be a violation of human rights for women to continue to be subjected to routine hospital maternity care that is demonstrably not backed by research evidence on what is best for most mothers and babies. Far from being an illness, childbirth is a healthy, normal, and important event in women's lives. Women deserve to receive the model of care backed by research evidence-namely, one on one care from a known competent midwife throughout pregnancy, birth, and postnatally, with obstetric back up for the minority of women $(10-15 \%)$ who need it.

Yet for most women now this model of care is unavailable. We implore all women everywhere to take heed of the options available to them and call for reforms to the maternity services in their countries so that all women have the choice of being cared for by their own midwife. In Australia we have proposed a national maternity action plan (www.communitymidwifery.iinet.net. $\mathrm{au} / \mathrm{nmap} . \mathrm{html}$ ) to inform governments and policy makers of the need for change.

Barbara Vernon national president

Maternity Coalition, PO Box 269, Lyneham ACT 2602, Australia

vernon@webone.com.au

Sally Tracy research midwife

Centre for Family Health and Midwifery, University of Technology Sydney, PO Box 123 Broadway, Sydney NSW 2007, Australia

Tracy Reibel administrator

Community Midwifery Program, East Fremantle WA 6158, Australia

1 O'Cathain A, Walters SJ, Nicholl JP, Thomas KJ, Kirkham M. Use of evidence based leaflets to promote informed choice in maternity care: randomised controlled trial in everyday practice. BMJ 2002;324:643-6. (16 March.)

2 Stapleton H, Kirkham M, Thomas G. Qualitative study of evidence based leaflets in maternity care. BMJ evidence bas

3 Editor's choice. BMJ 2002;324 (7338). (16 March.)

\section{Provision of information is only one component of informed choice}

EDITOR-Stapleton et al highlight the fact that provision of information is only one of the necessary conditions-and not a sufficient condition-for informed choice in the context of health care. ${ }^{1}$ Competence (of patients to understand choices), voluntariness (freedom from constraints and coercion), and decision making ability (making an actual choice) are also necessary.

Most antenatal patients are competent, but in the context of pregnancy care in the United Kingdom it is doubtful whether any decision is voluntary, given the attitudes and behaviour of some staff described in this study. In addition, patients are often not expected to make any decisions themselves but, as highlighted in this paper, are simply expected to comply with the policy of the obstetric unit, whatever that might be. It is thus not surprising that Stapleton et al found that their leaflet made little difference to the percentage of women reporting that they made informed choices.

Diane Reeves honorary clinical senior lecturer Department of General Practice, University of Birmingham, Birmingham B17 0SN

diane.reeves@medgp1.bham.ac.uk

1 Stapleton H, Kirkham M, Thomas G. Qualitative study of evidence based leaflets in maternity care. BMI 2002;324:639-43. (16 March.)

\section{Voluntariness must be ensured in prenatal screening}

EDITOR-Prenatal screening for Down's syndrome has largely developed as a consequence of advances in technology and the presumption that the NHS would provide it as a health related service. Whether the NHS should fund a test (or combination of tests) for this condition is questionable. But what is perhaps more worrying is a second presumption-the presumption of acceptance, the expectation of compliant behaviour.

Despite any intended neutrality the very act of offering screening for the syndrome intrinsically suggests that having information relating to the risk will be beneficial and empowering. ${ }^{1}$ Making the offer of a test mandatory can seem to a mother to be compulsion. Women have come to perceive screening for Down's syndrome as an integral part of antenatal care and may feel a responsibility to have it.

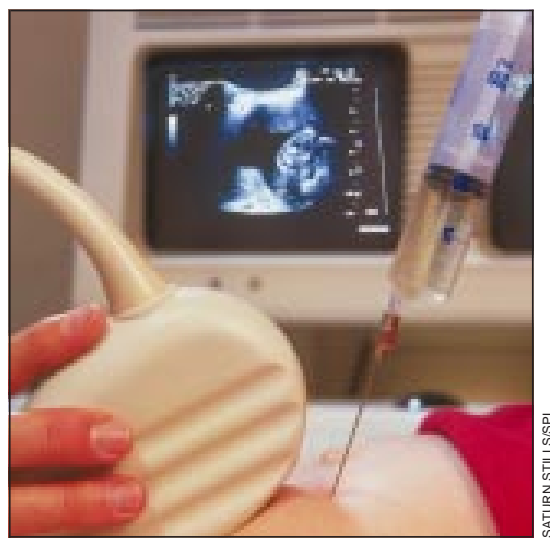

Screening for Down's syndrome is perceived as integral to antenatal care

Skrabanek has suggested that screening can be achieved only through coercion and deception and that it is invariably an infringement of personal liberty. ${ }^{2}$ Certainly in the antenatal setting issues of voluntariness and informational manipulation are raised. The observation that health professionals promote normative patterns of care and thus ensure informed compliance rather than informed choice has recently been given further credence. ${ }^{34}$

Clearly, the decision as to whether or not to be screened should rest on knowledge of potential benefits and remain free from social pressures and coercions. A woman may fear covertly expressed suggestions of rejection by her carers at a time when she wants to be seen to be doing the best for her 
baby. She may simply acquiesce to meet the terms of the service provided, her resistance having been weakened by her desire for the complete antenatal care package-almost entirely organised around the provision of prenatal screening tests, which in itself is a presumption of acceptance.

When considering issues of consent for prenatal screening most commentators concern themselves with adequacy of disclosure. It is, however, increasingly clear that the real issue in this situation is whether the "informed" choice is freely made.

James B Robins consultant obstetrician and gynaecologist

Inverclyde Royal Hospital, Greenock PA16 0XN James.Robins@irh.scot.nhs.uk

1 Hunt LM. Routine prenatal genetic screening in a public clinic: informed choice or moral imperative? Medical Humanities Report 2000;22(2):fall. (www.bioethics.msu.edu/ $\mathrm{mhr} / 01 \mathrm{w} /$ prenatalscreening.htm.)

2 Skrabanek P. Preventive medicine and morality. Lancet 1986;i:143.

3 Stapleton H, Kirkham M, Thomas G. Qualitative study of evidence based leaflets in maternity care. $B M$ 2002;324:639-43. (16 March.)

4 O'Cathain A, Walters SJ, Nicholl JP, Kirkham M. Use of evidence based leaflets to promote informed cho of dence based leaflets to promote informed choice in maternity care: randomised controlled trial in everyd
practice. BMJ 2002; 324:643-6. (16 March.)

5 Bowater $v$ Rowley Regis Corpn. [1944] KB 476 at 479.

\section{Domestic violence}

\section{It's not only men who commit domestic violence}

EDITOR-I am disappointed by Jewkes's editorial on domestic violence. ${ }^{1}$ The clear implication is that men are the oppressors and women suffer. Sadly this is often true, but it is far from being the whole picture.

The 1996 British crime survey asked a representative sample of 16500 adults in England and Wales directly about their experiences of crime, and whether it was reported to the police. The survey included a computer assisted self interviewing questionnaire, designed to give findings on the extent of domestic violence in England and Wales. The results found that $4.2 \%$ of women and $4.2 \%$ of men said that they had been physically assaulted by a current or former partner in the past year.

Many studies have found similar results. The work of Straus (a good example of which can be found at www.vix.com/ menmag/straus21.htm) is particularly authoritative. Indeed, when one considers that most violence against children is committed by women, in terms of gender it is women who are most likely to be perpetrators of domestic violence.

Does this manner of presentation matter? I think it does. On a personal level it leads to the situation I encountered recently in my local police station. A man with quite severe injuries after an attack by his former (female) partner was in the cells for breach of the peace. On a broader level it adds to the negative image of men that is so widespread in parts of our popular culture. This does nothing to help the forging of a masculine identity in certain vulnerable young men, which Jewkes says is a risk factor for violence.

Why, I wonder, is domestic violence so often portrayed in such a partisan and unscientific way?

Mark S Horner general practitioner

Felton, Northumberland NE65 9PR

ylw14@dial.pipex.com

1 Jewkes R. Preventing domestic violence. $B M$ 2002;324:253-4. (2 February.) 2 Home Office. British crime survey. London: HMSO, 1998.

Literature is biased as studies rarely look at female-to-male violence

EDITOR-Several papers in the $B M J$ have looked at domestic violence. ${ }^{123}$ Although this problem has been well documented, in the movement to expose it properly there is a gender bias that, ironically, betrays the underlying concern with gender equality.

The language of domestic violence reporting often makes a bold assumption by speaking exclusively of violence by men against women. The title of Richardson et al's paper is misleading. ${ }^{2}$ It implies that they are reporting a cross sectional study, but what the authors actually looked at was $50 \%$ of the population-namely, women. The title of Jewkes's editorial is gender neutral, yet the subtitle shows the exclusion, lamenting that women are not consistently asked about the possibility of domestic violence. This is not necessarily more misleading than the early studies of coronary artery disease, which were presumed to be inclusive though in fact studied only men.

The justification for this slant in the domestic violence literature has been that female victims vastly outnumber male victims. Many data, however, suggest otherwise. Cascardi et al found that $86 \%$ of marital aggression was reported as reciprocal between husbands and wives. ${ }^{4}$ Schafer et al reported lower and upper bounds on intimate partner violence of $5.21 \%$ and $13.61 \%$ for male-to-female partner violence and $6.22 \%$ and $18.21 \%$ for female-to-male partner violence. ${ }^{5}$ Interestingly, female-tomale violence was reported to be higher than male-to-female.

These data force a recognition that female-to-male violence must be included in any discussion. Bradley et al note that "there is generally no universally agreed method of defining and measuring domestic violence." A simple first step would be for the authors to recognise that, regardless of the precise percentages, this is a bi-directional, bi-gender issue. The authors lament that women are inconsistently asked about domestic violence, but they ignore the even greater lack of inquiry into men's potential victim status. This reporting bias may partly explain the disparity in the limited literature that attempts to include data on bi-directional violence.

None of the three articles in the $B M$ J even allude to female-to-male domestic violence. This reflects a literature bias that will undoubtedly influence future work. Such bias ignores many thousands of male victims and alienates those who demand a more balanced presentation.

Let's keep working to get better data, but let's recognise the bi-gender nature of this societal ill. That way, all of us can become involved in research, advocacy, and teaching and be part of the solution. In other words, "it is now time for the medical establishment to embrace the issue of gender."

Chris Carlsten resident in internal medicine

Department of Medicine, Box 356421, University of Washington, Seattle, WA 98195, USA

1 Bradley F, Smith M, Long J, O'Dowd T. Reported frequency of domestic violence: cross sectional survey of women attending general practice. BMJ 2002;324:271-4. (2 February.)

2 Richardson J, Coid J, Petruckevitch A, Wai SC, Moorey S, Feder G. Identifying domestic violence: cross-sectional study in primary care BMJ 2009.324.274-7. (2 February)

3 Jewkes R Preventing domestic violence BMJ 2002.324.253-4 (2 Febriary)

Cascardi M, Langhinrichsen J, Vivian D. Marital aggresCascard M, Langhimichsen J, Vivian D. Marital aggression. Impact, injury, and health conrelates for ho

5 Schafer J, Caetano R, Clark CL. Rates of intimate partner violence in the United States. Am J Public Healt $1998 \cdot 88 \cdot 1702-4$

\section{European sentinel network of practices has been established}

EDITOR-Two studies on domestic violence highlighted the lack of routine involvement of primary care practitioners ${ }^{1}$ and the difficulties in screening for domestic violence in general practice. ${ }^{2}$ These two studies are of great importance as European data on domestic violence are scarce.

Richardson et al concluded that the introduction of screening for domestic violence in healthcare settings is premature because of its limited acceptability (20\% of women said that they would mind being asked about it by their general practitioner), whereas Bradley et al observed that only $7 \%$ of women would mind such routine inquiry by their doctor.

Unlike Richardson et al, we find this rate of spontaneous acceptability high, and favourable for the adoption of this type of screening. After all, it is not done at present; other types of screening, such as that for breast, cervical, or prostate cancer, were probably greeted with similar views initially. Other authors report good sensitivity and good specificity from primary care questionnaires regarding severe violence by intimate partners. ${ }^{3}$

Why do doctors find it so difficult to recognise marital violence, even in cases of visible physical violence? A study in 2000 among 235 general practitioners in the Paris area showed that in only $7.7 \%$ of the cases of domestic violence finally recognised as such had the doctor raised the question of domestic violence. It also showed that most general practitioners do not know how to cope with this problem: $76 \%$ did not know of any structure or other professional able to help their patient, $60 \%$ declared themselves insufficiently trained to detect and provide follow up for domestic violence, $47 \%$ judged themselves unable to do so, and $21 \%$ declared that they had too little time to raise this question.

In view of these findings, a multilingual internet site was created in 2001 with the 
support of the European Union's Daphne initiative. It provides health professionals with information and recommendations for detecting female victims of domestic violence and providing follow up for them (www.sivic.org).

In addition, a European surveillance network of primary care practices (the Vigil network) now brings together health professionals (general practitioners, staff of emergency services, gynaecologists) and associations that help female victims of domestic violence in eight European countries. For each case recognised the volunteer doctors are questioned about how the violence was detected, their intervention, and the difficulties encountered. The female victims are also questioned about their contacts with health professionals (or why there were none) and the proposals that were made.

Cécile Morvant director

Institut de l'Humanitaire, 75014 Paris, France

Jacques Lebas specialist

Department of Internal Medicine, Hôpital

Saint-Antoine, 75012 Paris

Pierre Chauvin public health researcher Research Unit on Epidemiology and Information Sciences (INSERM U444), 75012 Paris pierre.chauvin@u444.jussieu.fr

1 Richardson J, Coid J, Petruckevitch A, Chung WS, Moorey S, Feder G. Identifying domestic violence: cross sectional study in primary care. BMJ 2002;324:274-7. (2 February.)

2 Bradley F, Smith M, Long J, O'Dowd T. Reported frequency of domestic violence: cross sectional survey of women attending general practice. BMJ 2002;324:271-4. (2 February.)

3 McNutt LA, Carlson BE, Rose IM, Robinson DA. Partner violence intervention in the busy primary care environment. Am J Prev Med 2002;22:84-91.

\section{Screening can be made acceptable to women}

EDITOR-We wish to highlight outcomes of the Queensland health domestic violence initiative, which incorporated screening for domestic violence into routine history taking protocols as a component of core clinical practice. ${ }^{1}$ The provider asks the client two or three additional questions relating to domestic violence during the history taking procedure. This small change has improved diagnosis and the provision of health services and information to women who experience domestic violence.

Respondents in the studies by Richardson et $\mathrm{al}^{2}$ and Bradley et $\mathrm{al}^{3}$ completed a self report questionnaire, but many had never been asked directly about domestic violence in a screening process. Only $12 \%$ of women in Bradley et al's study reported that their doctor had asked about domestic violence. In our study $83 \%$ of women presenting to the antenatal or gynaecology outpatient services were screened for domestic violence, with roughly $6.5 \%$ disclosing that some form of domestic violence had occurred. Of those women who were positive on screening, about $10 \%$ accepted help.

Clients thought that screening women for domestic violence was a good idea, with $97 \%$ of those surveyed supporting it. This is higher than the figures reported in the $B M J$ $(77 \%$ by Bradley et al and $80 \%$ by Richardson et al). Richardson et al report that at least $20 \%$ of women objected to screening. To determine the extent of acceptability more accurate conclusions can be drawn from research that reports on the views of women who have experienced personalised screening.

Richardson et al report that $42 \%$ of women would find it easier to discuss issue concerning domestic violence with a female doctor. Issues of gender, power, and interpersonal sensitivity must be considered when assessing people for domestic violence. Neither Richardson et al nor Bradley et al identified whether certain contexts were described in the questionnaire when investigating women's attitudes to screening. For example, a woman's attitude to screening about domestic violence might alter if the questions were asked in private with no family member present, if they were asked by a female health professional, if the woman perceived the health professional to be genuinely concerned about her, and if the woman was offered access to information and referral. Such issues need to be considered when investigating attitudes of service users.

The papers also report on the low rate of documentation of domestic violence-for example, only $17 \%$ of cases were documented in Richardson et al's paper. Our work identified that quick, simple, routine screening can be effective, with documented compliance of around $88 \%$ and $97 \%$ acceptability to women.

\section{Joan Webster director}

Nursing and Women's Health Research Centre, Royal Brisbane and Royal Women's Hospital, Post Office Herston 4029, Queensland, Australia joan_webster@health.qld.gov.au

Debra K Creedy professor of nursing and health Griffith University, Brisbane 4305, Queensland, Australia

1 Webster J, Stratigos S, Grimes K. Women's responses to screening for domestic violence in health care setting. Midwifery 2001;17:289-94.

2 Richardson J, Coid J, Petruckevitch A, Chung W, Moorey S, Feder G. Identifying domestic violence: a cross section study in primary care. BMJ 2002;324:274-7. (2 February.)

Bradley F, Smith M, Long J, O'Dowd T. Reporte frequency of domestic violence: cross sectional survey of women attending general practice. BMJ 2002;324:271-4 (2 February.)

\section{Sexual behaviour and its medicalisation}

\section{Many (especially economic) forces promote medicalisation}

EDITOR-The subject of the medicalisation of sexual behaviour requires an even larger perspective than that offered by Hart and Wellings, ${ }^{1}$ one specifically identifying socioeconomic trends and agents. For example, the addition of sexual dysfunctions to the American psychiatric nomenclature in 1980 came at a time when psychiatry needed to become more biological and quantitative to participate in new American insurance reimbursement plans. The Masters and Johnson list of disorders, focusing on dissatisfaction with genital arousal and orgasm but omitting "soft" problems of pleasure or intimacy, fitted these quantitative and biological needs but popularised standards for sexual satisfaction that are overly genital and performance oriented. ${ }^{2}$

The involvement of urologists in male sexual problems in the 1980s came about because of specialists' needs for new topics and patients, the encouragement of newly interested industries, and shifts in relations between academics and these industries. ${ }^{3}$ It was widely promoted in the press, creating heightened expectations about medical sexual expertise.

When Hart and Wellings cite epidemiological statistics for sexual problems they inadvertently contribute to the problems of medicalisation by citing weak research and failing to discuss how definitions of a problem play a part in market-driven medicalisation. American studies of the prevalence of sexual problems use overinclusive definitions-not surprising given the extent of drug company involvement in the research. ${ }^{4}$

A discussion of medicalisation needs to examine the fit between models of sexuality and the medical model. ${ }^{5}$ Hart and Wellings conclude that the problems of medicalisation are really those of overmedicalisation, but I believe that that is superficial. Sexuality is a social construction, and medicalisation is the new social construction. Excessive medicalisation may be malpractice, but we must question the fundamental model of sexuality as a biological rather than a sociocultural and political entity.

Hart and Wellings's final sentence ("The last century saw a considerable increase in acceptance of diversity of sexual expression-it would be a shame if this century saw diversity replaced by uniform expectations of performance and desire") is their strongest, but their analysis needs to be more comprehensive. I would direct readers to a new feminist campaign that has emerged to resist the for-profit medicalisation of women's sexual problems (www.fsdalert.org).

Leonore Tiefer clinical associate professor of psychiatry

New York University School of Medicine, New York, NY 10003 , USA

LTiefer@mindspring.com

1 Hart G, Wellings K. Sexual behaviour and its medicalisation: in sickness and in health. BMJ 2002;324:896-900.

2 Tiefer L Historical, scientific, clinical, and feminist criticisms of "the human sexual response cycle" mode Annual Review of Sex Research 1991;2:1-23.

3 Tiefer L In pursuit of the perfect penis: the medicalization Iif L. In pursuit of the perfect penis. hhe nedicalization of male sexuatic

4 Tiefer L. Sexology and the pharmaceutical industry: the threat of co-optation. J Sex Research 2000;37:273-83.

5 Tiefer L. The medicalization of sexuality: conceptual, normative, and professional issues. Annual Review of Sex Research 1996;7:252-82.

\section{HIV-AIDS prevention efforts deserved greater mention}

EDITOR-In their account of the medicalisation of sexual behaviour Hart and Wellings do not pay sufficient attention to the HIV-AIDS prevention efforts that were undertaken during the mid-1980s. ${ }^{1}$ They can be considered to be the most important 
effort to medicalise sexuality in the 20th century. The enormous amount of social, scientific, medical, and public health responses generated are evidence of the complex and multiple dimensions of such a process.

In the absence of a vaccine and a magic bullet against HIV and the disease it engenders, public health authorities had to develop a comprehensive prevention strategy. This included, firstly, national surveys on sexual behaviour in most industrial and developing countries to collect information on the sexual practices of the populations, to an extent never before achieved; secondly, a dramatic change of sexuality-related values and meanings (heterosexual intercourse becoming a major risk behaviour; masturbation considered to be a low risk practice, etc); and, thirdly, a global strategy of behaviour modification to promote behaviour change (systematic use of condoms, reducing the number of partners, etc).

An overall evaluation of the response to AIDS today shows, on the one hand, an insufficient response by public health authorities, as evidenced by the increasing numbers of HIV carriers in developing countries and among vulnerable groups in industrialised countries. On the other hand, it represents the most important and comprehensive effort at controlling sexual activity and changing its meaning on the global level.

In conclusion, Hart and Wellings would have given a more balanced analysis of the process of medicalisation of sexuality if they had included the responses to HIV infection and AIDS in their article.

Alain Giami director of research

INSERM U 569, 94276 Le Kremlin Bicêtre Cedex,

France

giami@vjf.inserm.fr

1 Hart G, Wellings K. Sexual behaviour and its medicalisation: in sickness and in health. BMJ 2002;324:896-900. (13 April.)

\section{Insulin pumps are still debatable for type 1 diabetes}

EDITOR-We have three comments about Pickup et al's meta-analysis comparing insulin infusion with injection, which may cast a different light on their main conclusion. ${ }^{1}$

Firstly, the results of the largest study in the meta-analysis, the so called Dusseldorf study, needs careful interpretation. The authors have estimated this study to show a positive result for continuous subcutaneous insulin infusion, with an advantage in percentage of glycated haemoglobin of $0.68 \%$. This figure will be an estimation made from a graph, as exact data are not given in the original paper. This seems to be a correct interpretation of the six month data of this study, but the total duration of the study was two years. At 12, 18, and 24 months the "advantage" of continuous subcutaneous insulin infusion can be estimated to be $0.35 \%,-0.1 \%$, and $-0.2 \%$, respectively. Thus another interpretation of this one study, representing 918 months of the meta-analysis's total of 2522 patient months of pump treatment, will have a substantial impact on the overall outcome of the metaanalysis.

Secondly, the authors did not include the study of Reeves et al in their analysis. This study, albeit small, did not show a difference in glycated haemoglobin between intensified injection therapy and insulin pump therapy. ${ }^{2}$

Thirdly, modified rapid acting insulins have recently been shown to be advantageous with respect to glycated haemoglobin. ${ }^{34}$ The most relevant comparison is therefore between continuous subcutaneous insulin infusion and multiple injection therapy, both using rapid acting insulin analogues.

Only two such studies have been published. The first, by Hanaire-Broutin et a and included in the meta-analysis, found a $0.35 \%$ lower glycated haemoglobin with insulin pump therapy than with injection therapy in 41 patients using a crossover design. However, patients had been receiving insulin pump therapy with human regular insulin for a mean of 5.5 years before entering the trial, which limits the external validity of this study. The second study, by Tsui et al, was published too recently to be included in the meta-analysis but did not show a difference in glycated haemoglobin over nine months in 21 patients.

We consider that the case for insulin pump treatment in type 1 diabetes has still to be decided. Two large multicentre trials comparing this treatment with optimised injection schemes with rapid acting analogues have been recently completed and should provide clinically useful information.

J Hans DeVries endocrinologist

hans.devries@vumc.n

Robert J Heine professor of diabetology

VU Medical Centre, Diabetes Centre, PO Box 7057 1007 MB, Amsterdam, Netherlands

1 Pickup J, Mattock M, Kerry S. Glycaemic control with continuous subcutaneous insulin infusion compared with thuor subla meta-analysis of rectons in patients with type 1 diabetes: 2002,324:705-8. (23 March.)

2 Reeves ML, Seigler DE, Ryan EA, Skyler JS. Glycemic control in insulin-dependent diabetes mellitus. Comparison of trol in insulin-dependent diabetes mellitus. Comparison of outpatient intensified conventional therapy with continu80.

3 Raskin P, Guthrie RA, Leiter L, Riis A, Jovanovic L. Use of insulin aspart, a fast-acting insulin analog, as the mealtim insulin in the management of patients with type 1 diabetes. Diabetes Care 2000;23:583-8.

4 Home PD, Lindholm A, Riis A. Insulin aspart vs. human insulin in the management of long-term blood glucose control in Type 1 diabetes mellitus: a randomized controlled trial. European Insulin Aspart Study Group. Diabetes Med 2000;17:762-70.

5 Tsui E, Barnie A, Ross S, Parkes R, Zinman B. Intensive insulin therapy with insulin lispro: a randomized trial of continuous subut daily insulin injection. Diabetes Care 2001;24:1722-7.

\section{Tourists travelling to Kilimanjaro do need advice}

EditoR-As Bellis's letter confirms, many tourists attempting the ascent of Kilimanjaro come ill prepared for the climb. ${ }^{1}$ We have treated tourists on the mountain for a

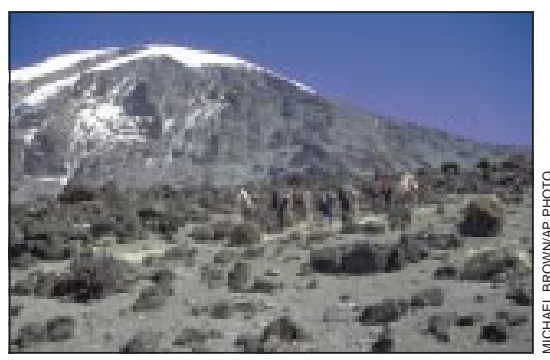

Tourists travelling to Kilimanjaro are regularly treated for severe altitude sickness

range of conditions, including high altitude cerebral and pulmonary oedema. In one instance we chanced on a traveller who was both frankly cyanotic and ataxic at an altitude of $3500 \mathrm{~m}$ and treated him with the last spare course of dexamethasone. We insisted that he descend, to the chagrin of his guide, who was encouraging him to continue his ascent. As some guides receive incentives to get tourists to the summit, this type of incident will undoubtedly recur.

Guides are generally drawn from the local population and have little training in first aid or the emergency management of altitude sickness. A helpful measure might be to set up basic training for guides that encompasses basic first aid and indications for descent. This initiative would, we believe, have to come from the travel industry.

We support the contention that tour operators and travel agents must issue the necessary warnings. Some tour operators do, providing printed material, referral to a travel clinic, and orientation lectures to travellers before departure; others, however, exercise less responsibility. Unfortunately, there seems to be little enforcement of the common law requirement for tour operators and travel agents to fulfil their admonitory obligations.

Inquiry at the Kilimanjaro Christian Mission Hospital at the base of Kilimanjaro confirmed that it regularly treats tourists with severe altitude sickness. Until a high profile claim is brought against negligent operators and agents we expect that it will continue to receive such patients. We suspect that the solution to this problem will ultimately come from the legal and not the medical profession.

Stephen Toovey medical director

Netcare Travel Clinics, PO Box 786692, Sandton, 2146, South Africa

toovey@travelclinic.co.za

Andrew Jamieson medical director

Netcare Travel Clinics, South Africa and

Mozambique, PO Box 573, Sunninghill, 2157,

South Africa

1 Bellis F. Tour operators should tell clients about potential risks of adventure holidavs. BMJ 2002;324:1040.(27 April.)

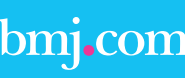

\section{Rapid responses}

Correspondence submitted electronically

is available on our website 